\title{
Laser Surface Alloying of SUS316 Stainless Steel with Al-Si* (Effect of Substrate Temperature on Structure and Properties of Modified Layer)
}

\author{
Sergey ZHEREBTSOV ${ }^{* *}$, Katsuhiro MAEKAWA ${ }^{* * *}$, \\ Terutake HAYASHI*** and Masatoshi FUTAKAWA***
}

\begin{abstract}
The effect of varying temperature of the type 316 stainless steel substrate on the structure and properties of laser alloyed layer was investigated. The material for alloying (Al-Si powder mixture) was placed on the surface of stainless steel substrate by pasting. The surface was scanned by a pulsed Nd: YAG laser beam to achieve surface alloying. The temperature of substrate continuously increased during laser treatment to about $830^{\circ} \mathrm{C}$. The microstructure, chemical and phase composition and microhardness of the modified layer were studied then. It has been found that four different types of structure were formed in the alloyed zone depending on the temperature of the substrate. These structures differ from each other in phase composition, microhardness and relation to cracking. Based on the results, optimal parameters for the production of a uniform, crack-free layer with a high hardness were developed.
\end{abstract}

Key Words: Laser Alloying, Stainless Steel, Aluminum-Silicon Powder, Temperature, Structure

\section{Introduction}

Attack due to corrosion and cavitation erosion is a common problem of structural materials in contact with severe environments. Various techniques and materials have been employed to modify the surface layer for increasing corrosion and/or erosion resistance. One of the attractive methods to improve properties of the surface is laser alloying, because of formation of a small heataffected zone leaving the bulk properties unchanged and the possibility of forming novel surface alloys unattainable by other methods. Relatively high rate of processing, ease of automation, possible operation at atmospheric pressure are other advantages of laser alloying over conventional surface modification techniques ${ }^{(1)-(10)}$.

* Received 18th May, 2005 (No. 05-4109)

** Satellite Venture Business Laboratory, Ibaraki University, 4-12-1 Nakanarusawa-cho, Hitachi-shi, Ibaraki 3168511, Japan. E-mail: sergeyzh@mx.ibaraki.ac.jp

*** The Research Center for Superplasticity, Faculty of Engineering, Ibaraki University, 4-12-1 Nakanarusawa-cho, Hitachi-shi, Ibaraki 316-8511, Japan.

E-mail: mae@mx.ibaraki.ac.jp

**** Japan Atomic Energy Research Institute, Tokai-mura, Naka-gun, Ibaraki 319-1112, Japan
However, the improved surface properties are very dependent on the laser alloying condition. The process is controlled by a large number of parameters, such as laser power, scanning speed, overlapping ratio, thickness of deposited layer and diameter of the laser beam. In order to achieve a desirable structure and properties of the modified layer a certain combination of those parameters should be used.

Successful attempts to optimize some laser alloying parameters for different materials combinations have been done in a number of works ${ }^{(3)-(6)}$. At the same time, influence of such an important laser process parameter as temperature of the substrate (not the temperature of the local zone under the laser beam, but the temperature of the whole specimen) on the structure and properties of improved surface is not investigated sufficiently yet. Meanwhile in the case of laser alloying the laser is used as a heat source above all, so that temperature of a substrate during laser treatment can play an important role in the formation of uniform, defect-free modified layer. In particular, it was reported that the improved surface produced by laser nitriding or laser alloying of preheated specimens contains much fewer defects, such as pores and cracks, than those without preheating ${ }^{(5),(7),(8)}$. 
Austenitic stainless steels are widely and historically used in corrosive environments, especially in nuclear reactor plants. However, owing to relatively low resistance to cavitation erosion, their applications are somehow limited. It has been shown in Refs. (1) and (2) that laser alloying of the type 316 stainless steel with Al-Si powders considerably improves microhardness and cavitation erosion resistance. However the process was not fully optimized, because small cracks were observed in the modified layer. Since the relation to cracking of the alloyed layer can be dependent on the temperature of substrate during alloying $^{(11)}$, it seems to be very important to define the relationship between the structure and properties of the modified layer and current temperature of the sample.

Therefore, the present work aimed to evaluate an influence of temperature of the substrate during laser alloying on the structure and properties of the modified layer.

\section{Materials and Methods}

\subsection{Laser surface alloying}

Austenitic stainless steel type SUS 316, with a chemical composition of $16.79 \mathrm{Cr}, 10.3 \mathrm{Ni}, 2.16 \mathrm{Mo}, 1.17$ $\mathrm{Mn}, 0.06 \mathrm{C}, 0.68 \mathrm{Si}, 0.027 \mathrm{P}, 0.001 \mathrm{~S}$ and balance $\mathrm{Fe}$ in wt.\%, was used as a substrate material. The specimens of $10 \times 10 \times 2 \mathrm{~mm}^{3}$ were cut from a $2 \mathrm{~mm}$ thick plate. Laser treatment was carried out using a pulsed Nd:YAG laser (wavelength of $1.06 \mu \mathrm{m}$ ) with a spot size of $0.36 \mathrm{~mm}$ in diameter. The flow of argon was used as a shielding gas. The specimens to be alloyed were put on an aluminum or ceramic plate during laser treatment.

Powder placed as slurry on the surface of the sample consisted of reagent grade $\mathrm{Si}$ and $\mathrm{Al}$ in the weight ratio of 2:3. The use of this proportion allows producing modified layers with high microhardness and cavitation erosion resistance ${ }^{(1)}$. The slurry was prepared by mixing the powders with an organic binder. The composition of the binder included n-decyl alcohol, n-tridecyl alcohol, ethylcellulose, ethanol and castor oil. The specimens painted with the slurry were dried on a hot plate for 4 hours at $250^{\circ} \mathrm{C}$. The thickness of the layer was controlled with an accuracy of $\pm 0.01 \mathrm{~mm}$ by precise polishing on a \#1000 grinding paper. Laser alloying of $7 \times 7 \mathrm{~mm}^{2}$ area was carried out then by melting of the painted surface (Fig. 1).

Preheating of samples before laser treatment was carried out by using the hot plate. The temperature of the hot plate was $300^{\circ} \mathrm{C}$. Samples were heated for $15 \mathrm{~min}$ and then they were moved to the ceramic plate for the laser treatment. The time between the stop of heating and the start of alloying was 70-80 s. The temperature of the samples at the start of laser treatment was $177 \pm 2^{\circ} \mathrm{C}$.

A special chamber was used for alloying of samples at elevated temperature (required temperature was maintained during alloying) (Fig. 2). The hot plate was installed within the chamber. An aluminum alloy plate

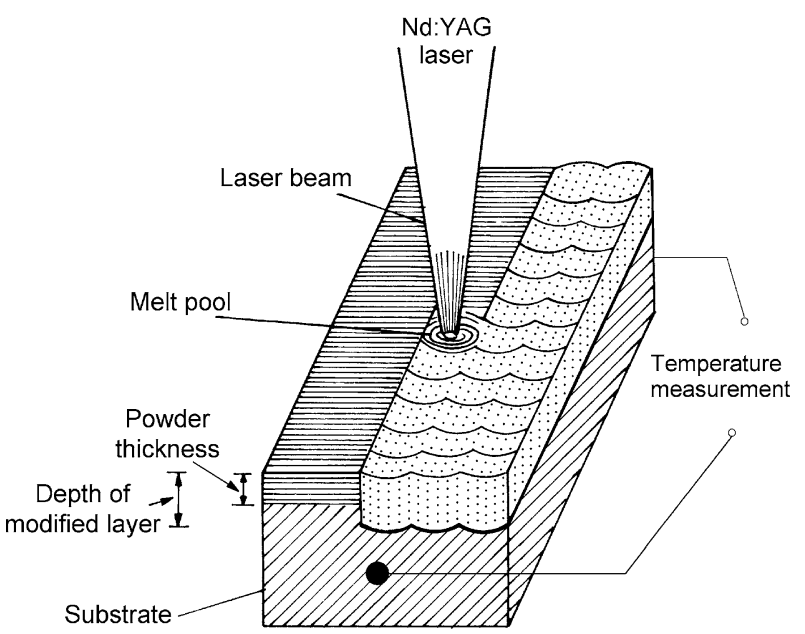

Fig. 1 Scheme of laser alloying procedure

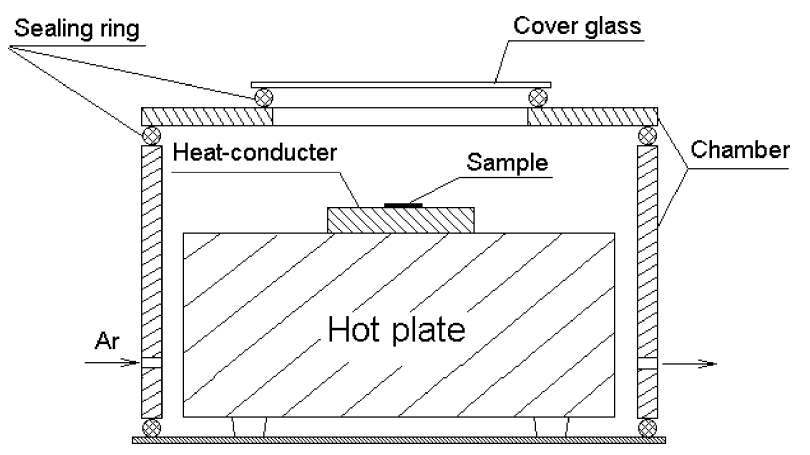

Fig. 2 Chamber for high-temperature alloying

was used as a heat-conductor between the hot plate and the samples. The chamber was covered with thermoresistance glass. As the transparency of the thermoresistance glass is lower than that of usual glass, the diameter of the laser beam increased to $0.42 \mathrm{~mm}$. The flow of argon gas was used for shielding. The maximum temperature of the hot plate was $350^{\circ} \mathrm{C}$.

To estimate the temperature of the substrate during alloying chromel and alumel wires were welded to the opposite faces of a rectangular SUS 316 specimen (with dimensions of $10 \times 10 \times 2 \mathrm{~mm}^{3}$ ) (Fig. 1). Then the laser beam was irradiated on the specimen under required conditions, and the temperature of the whole specimen was registered as a function of time.

After laser treatment, the alloyed surfaces and crosssections of the specimens were polished and etched. The microstructure and chemical composition of the laser melted zone were analyzed by optical microscopy, scanning electron microscopy and energy dispersive X-ray spectroscopy. The microhardness of alloyed zones was measured in cross sections and along the surface. Phase composition was evaluated by means of X-ray analysis.

\subsection{Selection of laser alloying parameters}

The process of laser alloying is very complicated because of many variable parameters. Every parameter has 
Table 1 Values of laser alloying parameters

\begin{tabular}{|l|c|}
\hline Frequency of pulsing, $\mathrm{Hz}$ & 100 \\
\hline Pulse voltage, $\mathrm{V}$ & 220 \\
\hline Pulse duration, $\mathrm{ms}$ & 2.5 \\
\hline Output energy, $\mathrm{W}$ & 0.88 \\
\hline Laser beam scanning speed, $\mathrm{mm} / \mathrm{min}$ & 200 \\
\hline Energy density, W/mm ${ }^{2}$ & 0.76 \\
\hline Thickness of placed powder, $\mathrm{mm}$ & $0.27-0.28$ \\
\hline
\end{tabular}

an influence on the structure and properties of the modified layer. Therefore, we have to optimise those parameters before evaluating an influence of the temperature on the quality of the alloyed zone.

The energy absorbed by material during laser alloying is consumed for melting the powder and a portion of underlying substrate (here the laser is seen as a simple heat source). Hence, to produce a proper alloyed zone the laser beam power must be higher than a certain threshold value. This value depends on a chemical composition and the thickness of the placed powder.

The laser beam in a pulsed laser machine has a number of parameters, including frequency of pulsing, pulse voltage and pulse duration. However, each of them in general has similar influence on the depth of the alloyed layer; namely, if the value of the parameter becomes higher, the thickness of the melted layer increases. Therefore, it is more convenient to operate with a combined parameter, that is energy density which includes all of the mentioned parameters plus beam scanning speed.

The experiments have shown that the energy density must be above $0.4 \mathrm{~W} / \mathrm{mm}^{2}$ for our case (Al-Si powders mixture, the thickness of the placed layer is more than $0.1 \mathrm{~mm}$ ) to produce a suitable melted zone. On the other hand, the use of excessive beam energy can lead to undesirable effects ${ }^{(10)}$ without a noticeable increase in thickness of the melted zone. Hence, the energy density which can be used for the laser alloying is confined within 0.4$0.9 \mathrm{~W} / \mathrm{mm}^{2}$ for the present case.

\subsection{Thickness of placed powder}

The thickness of the placed powder is another important factor for a laser alloying process. Change in the thickness of the placed powder leads to change in quality (in terms of homogeneity, cracking and porosity) of the alloyed zone. Preliminary results have shown that the optimal thickness of the placed powder layer should be confined within $0.25-0.30 \mathrm{~mm}$ for the given parameters of laser alloying (Table 1). Higher power density allows utilizing thicker powder layer. However, an excessive power makes the process of laser alloying poorly controllable.

The values of the parameters used in the present paper are listed in Table 1.

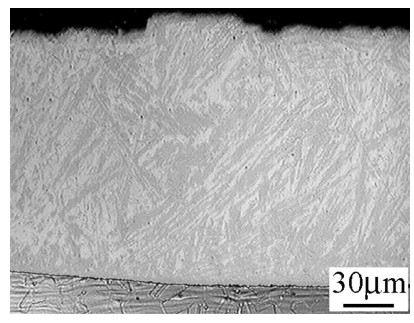

(a)

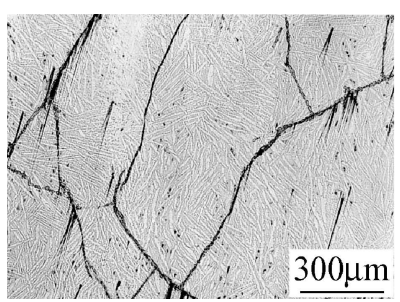

(c)

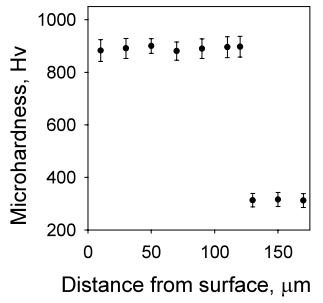

(b)

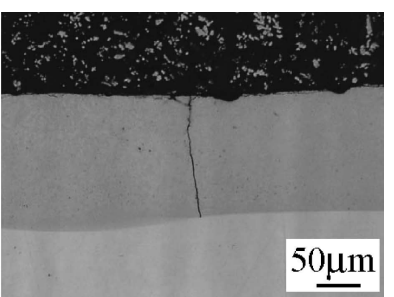

(d)
Fig. 3 Microstructures (a, c, d) and microhardness (b) of alloyed layer. Cross-section (a, b, d) and polished surface (c) of laser treatment zone

\section{Results}

\subsection{Laser alloying without preheating}

The results of laser alloying according to the parameters listed in Table 1 are shown in Fig. 3. The microstructure of the modified layer mainly consists of lamellar $\mathrm{FeAl}_{3}$ intermetallic compound (Fig. 3(a)). The microhardness of the modified layer is about 2.5 times higher than that of the untreated substrate (Fig. 3 (b)). However, many cracks and pores are observed in the modified layer (Fig. 3 (c)). The cracks, as a rule, penetrate throughout the modified layer (Fig. 3(d)). Besides, the microstructure of the laser alloyed zone is heterogeneous. In some peripheral areas of the laser treated zone, the microstructure includes soft Al-Si eutectic, which makes the microhardness of such zones extremely low.

Simple variation of the laser alloying parameters discussed above did not allow avoiding cracking in the modified layer. Meanwhile, one of the promising ways to prevent cracking is preheating of samples before laser treatment $^{(5),(7),(8)}$.

\subsection{Effect of temperature of substrate on mi- crostructure and properties of laser alloyed layer}

To evaluate in details the effect of temperature of the substrate on the microstructure and properties of laser alloyed layer, the following experiment has been conducted. The specimen with placed $\mathrm{Al}-\mathrm{Si}$ powder was preheated to $300^{\circ} \mathrm{C}$ after that it was moved to a ceramic plate (temperature at the start of laser treatment was $177^{\circ} \mathrm{C}$ ). Then the specimen was laser treated under the conditions listed in Table 1. Because the specimen contacted with the ce- 
ramic plate only, its cooling rate was slow. Hence the temperature of the specimen increases continuously during laser treatment (Fig. 4). The temperature of the specimen changes significantly during laser alloying; from $170^{\circ} \mathrm{C}$ to $830^{\circ} \mathrm{C}$. At the initial stages of the laser treatment the temperature increases fast and then becomes steady at about $830^{\circ} \mathrm{C}$

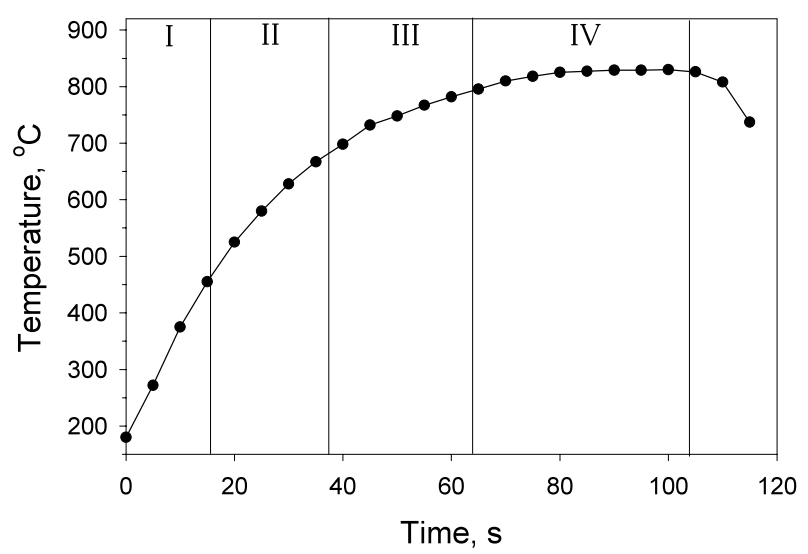

Fig. 4 Change in temperature of sample during laser alloying. Energy density $76 \mathrm{~W} / \mathrm{mm}^{2}$, scanning area $7 \times 7 \mathrm{~mm}^{2}$, laser treatment duration $100 \mathrm{~s}$, (marked areas are approximately corresponded to zones with different microstructures, see below)

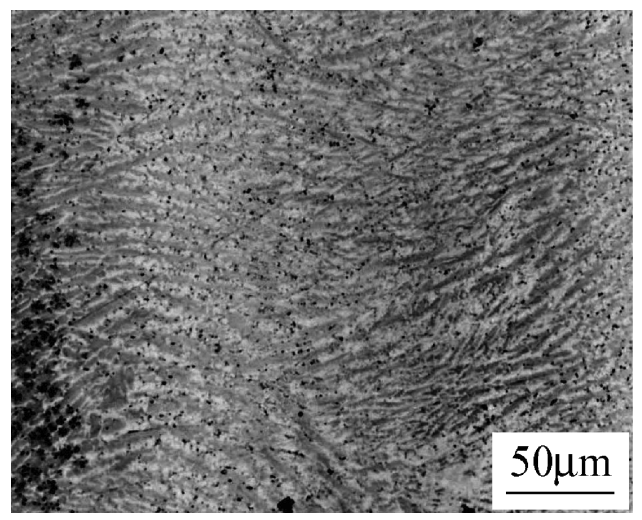

(a)

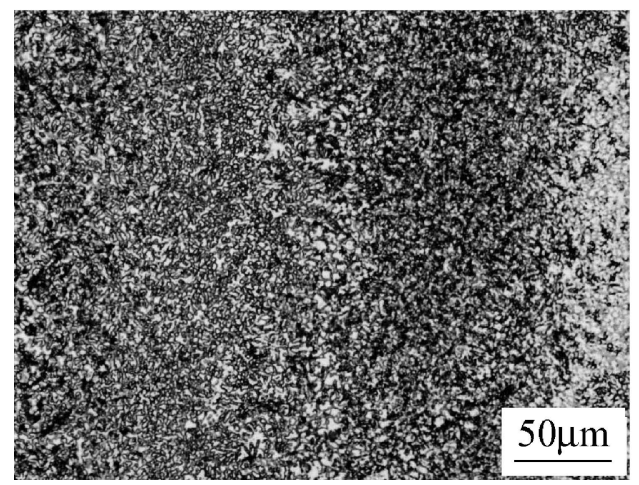

(c)
Four zones can be distinguished in the alloyed surface after polishing and etching (Figs. 5 and 6). Those zones differ from each other in microstructure, microhardness and relation to cracking.

It is clearly seen that the microstructures in the zones are different (Fig. 6). Zone I has a lamellar type of microstructure (similar to that shown in Fig. 3 (a)), Zones II

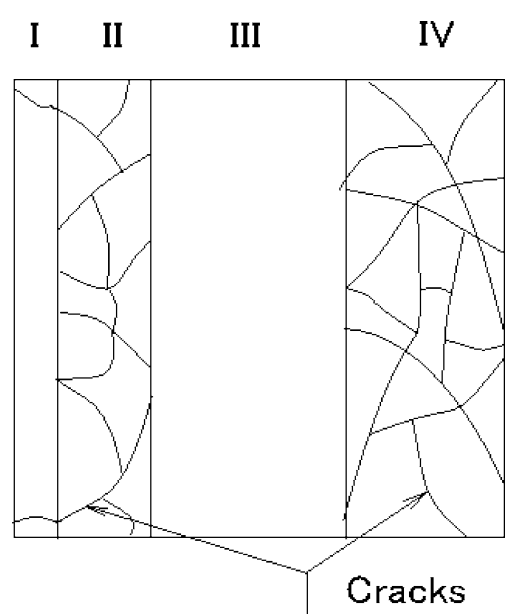

Fig. 5 Sketch of location of zones with different microstructure in alloyed sample

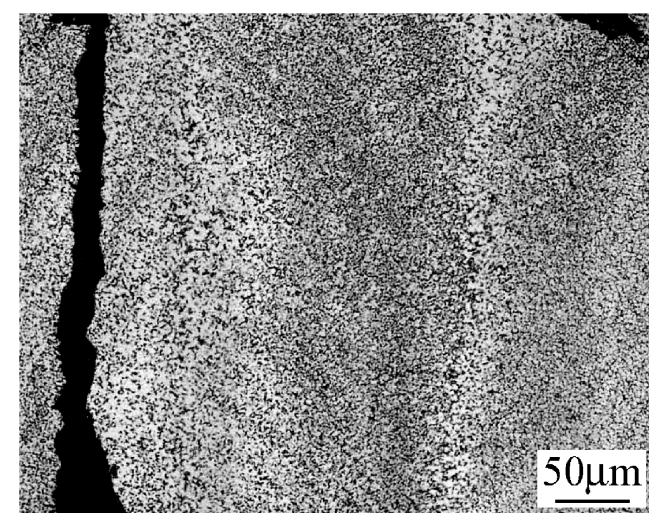

(b)

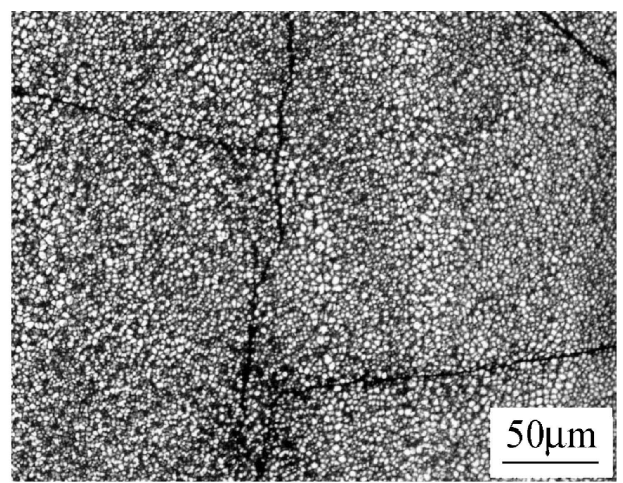

(d)

Fig. 6 Microstructures of zones one through four: (a) Zone I, (b) Zone II, (c) Zone III, (d) Zone IV 
and III have different types of dendritic structure and Zone IV has a globular type of microstructure.

Cracking in the alloyed area is also strongly associated with the zones. The third zone has no cracks at all. Just a few cracks in the periphery areas are seen in the first zone. Meanwhile, there are many cracks in Zones II and IV.

Chemical composition and microhardness of those microstructures are also quite different (Table 2). Percentages of $\mathrm{Al}$ and $\mathrm{Si}$ decrease with increasing of number of zone, while percentage of $\mathrm{Fe}$ and $\mathrm{Cr}$ increases with

Table 2 Distribution of chemical elements and microhardness in laser alloyed area

\begin{tabular}{|c|c|c|c|c|}
\hline \multirow{2}{*}{$\begin{array}{c}\text { Elements, } \\
\text { wt\% }\end{array}$} & \multicolumn{4}{|c|}{ Type of zone } \\
\cline { 2 - 5 } & I & II & III & IV \\
\hline $\mathrm{Al}$ & 22.26 & 18.83 & 17.6 & 10.18 \\
\hline $\mathrm{Si}$ & 14.89 & 13.32 & 11.17 & 8.55 \\
\hline $\mathrm{Cr}$ & 11.39 & 11.71 & 12.81 & 13.96 \\
\hline $\mathrm{Fe}$ & 43.82 & 48.72 & 51.38 & 58.78 \\
\hline $\mathrm{Ni}$ & 7.64 & 7.42 & 7.03 & 8.52 \\
\hline Microhardness, Hv & $893 \pm 9$ & $841 \pm 10$ & $885 \pm 5$ & $626 \pm 12$ \\
\hline
\end{tabular}

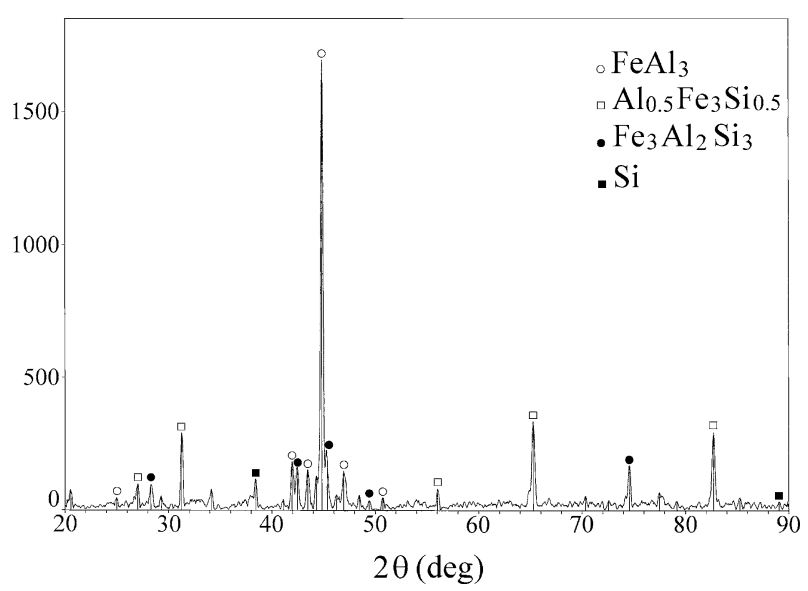

Fig. 7 X-ray diffraction spectra of SUS316 specimen alloyed with $\mathrm{Al}$ and $\mathrm{Si}$ at substrate temperature of $170-830^{\circ} \mathrm{C}$

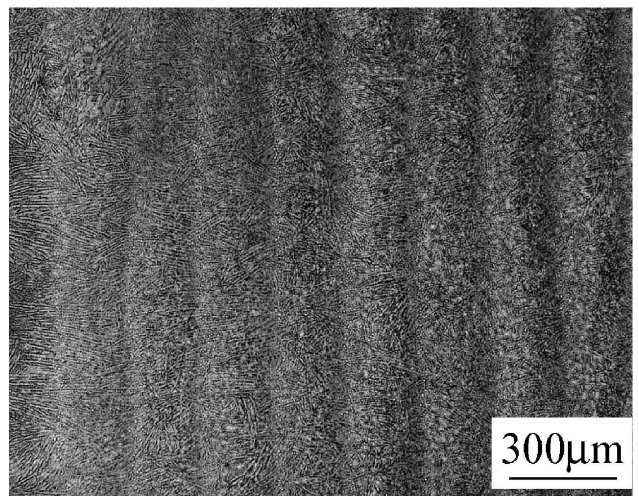

increasing number of zone. Percentage of Ni does not change noticeably in the whole investigated area. Microhardness of the alloyed area decreases with increasing number of zone except Zone III. Microhardness of Zone III is quite high and is similar to that of Zone I. For comparison, the microhardness of unalloyed substrate is $315 \mathrm{Hv}$.

$\mathrm{X}$-ray analysis revealed that the modified layer consists of $\mathrm{FeAl}_{3}$ intermetallic compound and composite $\mathrm{Fe}$ $\mathrm{Al}-\mathrm{Si}$ intermetallic phases like $\mathrm{Fe}_{3} \mathrm{Al}_{2} \mathrm{Si}_{3}$ and $\mathrm{Al}_{0.5} \mathrm{Fe}_{3} \mathrm{Si}_{0.5}$ (Fig. 7). It also can be distinguished small peaks matched with $\mathrm{Cr}-\mathrm{Al}$ and $\mathrm{Cr}$-Si phases.

From a practical viewpoint, it would be attractive to get the structure that was observed in Zone III. However, the microstructure in this zone was produced when the temperature of substrate was as high as $750^{\circ} \mathrm{C}$. Obviously, this temperature is too high for engineering applications. More interestingly, that the central part of the first zone, which was attained at the temperature below about $450^{\circ} \mathrm{C}$, is crack-free also. As the formation of a certain type of microstructure is strongly associated with the temperature of the substrate during alloying (if the other parameters are fixed), the special chamber was used for alloying at a substrate temperature of $350^{\circ} \mathrm{C}$ (Fig. 2).

\subsection{Laser alloying at elevated temperature of sub- strate}

Laser alloying at $350^{\circ} \mathrm{C}$ produced a microstructure corresponding to Zone I (or to the microstructure attained by laser alloying without preheating) (Figs. 3 (a) and 6 (a)). The microhardness $(887 \pm 7 \mathrm{Hv})$ was also similar to that observed for the microstructure produced by laser alloying without preheating (Fig. 3(b)) or for Zone I of the specimen alloyed at continuously increased temperature (see Table 2). However, a doubtless advantage of laser treatment at $350^{\circ} \mathrm{C}$ is the formation of a homogeneous, dense, crack-free modified area. The thickness of the improved layer is $130 \mu \mathrm{m}$. The microstructure of the specimen after high-temperature alloying is shown in Fig. 8.

Fig. 8 Microstructures of improved layer after laser alloying at $350^{\circ} \mathrm{C}$ : energy density $0.76 \mathrm{~W} / \mathrm{mm}^{2}$, scanned area $7 \times 7 \mathrm{~mm}^{2}$, thickness of powder $0.27 \mathrm{~mm}$ 


\section{Discussion}

The results obtained in the present work show a strong dependence of structure and properties of the laser alloyed layer on the temperature of the substrate (if other parameters are fixed). Let's discuss causes of the formation of a certain type of structure in the alloyed layer. The experiment described in section 3.2 is illustrated in Fig. 9. At all fixed parameters the temperature only increases as laser beam moves from left to right (Fig. 9 and also see Fig. 1). Increase in temperature leads to a continuous extension of the heat-affected zone (both in diameter and in depth) and to increase in volume of melts. As the thickness of powder is constant, the volume of melts increases owing to the melting of the substrate material mainly (stainless steel). Hence, the ratio of chemical elements in the melt changes continuously during alloying. In particular, the percentages of $\mathrm{Al}$ and Si decrease whereas the percentages of $\mathrm{Fe}$ and $\mathrm{Cr}$ increase (Table 2).

As it can be seen in the Fe-Al phase diagram ${ }^{(12)}$ (Fig. 10), moving along the concentration axis (or changing $\mathrm{Fe} / \mathrm{Al}$ ratio in the melt) leads to the formation of different $\mathrm{Fe}-\mathrm{Al}$ intermetallic compounds or solids solutions.

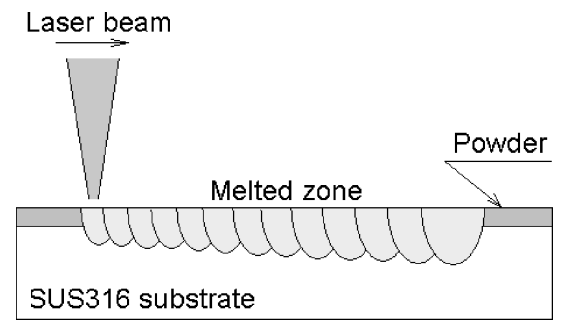

Fig. 9 Change in size of melt during laser alloying
Taking into account the results of X-ray analysis and measurement of the chemical composition, it can be concluded that the modified layer consists of $\mathrm{FeAl}_{3}$ as a major phase. Increase in contents of $\mathrm{Fe}$ in the melt leads to the formation of Fe-rich phases like $\mathrm{Fe}_{3} \mathrm{Al}_{2} \mathrm{Si}_{3}$ and $\mathrm{Al}_{0.5} \mathrm{Fe}_{3} \mathrm{Si}_{0.5}$. Simultaneously, the hardness of the structure has a trend to decreasing while content of Fe increases.

In addition, increase in temperature increases the rate of diffusion processes. As a result, the alloyed zone becomes enriched with the elements from the substrate (Table 2). Apparently, this process promotes the formation of phases like Al-Cr and Si-Cr.

The appearance of cracks in Zones II and IV (Fig. 6) is obviously associated with thermal stresses arising during solidification ${ }^{(5),(8)}$. While cooling, the molten alloy undergoes inevitable shrinkage due to constraints imposed by the surrounding material. Tensile stresses of the order of or more than yield strength can be generated ${ }^{(13)}$. Cracking takes place as the solidified alloy does not have sufficient ductility to accommodate these stresses. Hence relation to cracking of the certain alloy depends on the extent of shrinkage during solidification (or the magnitude of tensile stresses) on the one hand and on the ductility of the alloy on the other hand. The relation of some Al-Fe-Si alloys to cracking during solidification was also mentioned in the literature ${ }^{(14)}$. In our case Zones I and III (Fig. 6) have no (or have only few) cracks, whereas many cracks are seen in Zones II and IV.

Consequently, thermal stresses should be decreased to prevent cracking in the laser alloyed layer. The thermal stress $\sigma$ resulting from a temperature change from $T_{0}$ to $T_{f}$ is commonly described as follows ${ }^{(15)}$ :

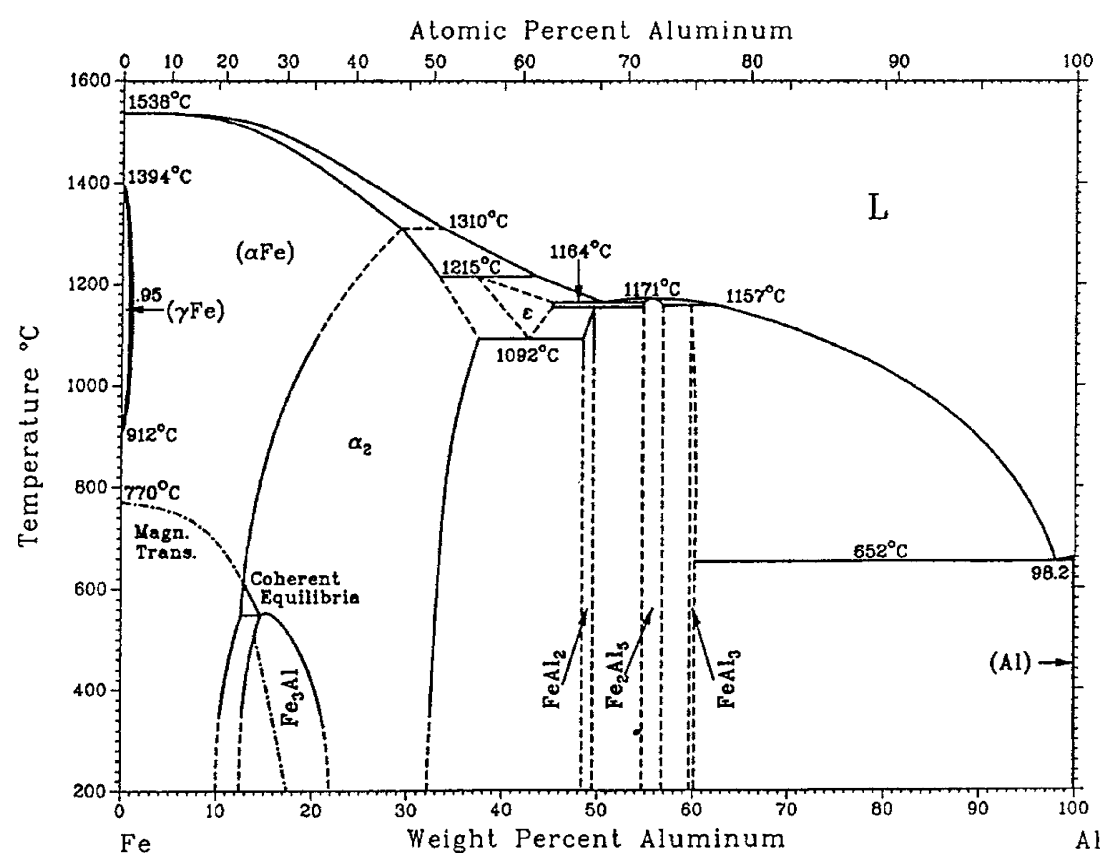

Fig. 10 Phase diagram of Fe-Al system ${ }^{(12)}$ 


$$
\sigma=\alpha_{l} E \Delta T,
$$

where $\alpha_{l}$ is the linear coefficient of thermal expansion and $E$ is the modulus of elasticity. Increase in temperature of the substrate decreases $\Delta T$ and decreases thermal stress $^{(11)}$. Indeed, the modified layer produced by alloying without preheating has many cracks (Fig. 3). Zone I has few cracks on the periphery where the temperature of substrate was lower (Figs. 5 and 6 (a)). The same structure produced by laser alloying at $350^{\circ} \mathrm{C}$ has no cracks at all.

Another important advantage of the alloying under continuously increasing temperature is a methodological worth. This experiment (being realized for any other powder/substrate combination) is capable to clear the influence of laser alloying parameters on the structure of alloyed layers. For instance, it is easy to see that increase in power density or decrease in thickness of powder layer has the same effect as increasing of temperature. Changes in those parameters in such manner lead to the enrichment of a melt with the substrate material ( $\mathrm{Fe}$ and $\mathrm{Cr}$ in our case) and to the formation of other types of structure. Hence, this experiment allows predicting and controling the structure and properties of the alloyed layer easily.

\section{Conclusion}

The effect of temperature on the structure and properties of the type 316 stainless steel alloyed with Al-Si has been reported in the present paper. It has been found that four different types of structure are formed in the alloyed zone depending on the temperature of the substrate. These structures differ from each other in phase composition, microhardness and relation to cracking. Hard, crackfree microstructures are formed at temperatures of about 350 and $750^{\circ} \mathrm{C}$. Maintaining the temperature of the sample at $350^{\circ} \mathrm{C}$ a uniform, crack-free layer with a high hardness is produced by laser alloying with an energy density of $0.76 \mathrm{~W} / \mathrm{mm}^{2}$.

\section{References}

( 1 ) Kwok, C.T., Cheng, F.T. and Man, H.C., Laser Surface Modification of UNS S31603 Stainless Steel. Part I: Microstructures and Corrosion Characteristics, Mater. Sci. Eng., A, Vol.290 (2000), pp.55-73.

( 2 ) Kwok, C.T., Cheng, F.T. and Man, H.C., Laser Surface Modification of UNS S31603 Stainless Steel. Part II:
Cavitation Erosion Characteristics, Mater. Sci. Eng., A, Vol.290 (2000), pp.74-88.

( 3 ) Senthil Selvan, J., Soundararajan, G. and Subramanian, K., Laser Alloying of Aluminum with Electrodeposited Nickel: Optimisation of Plating Thickness and Processing Parameters, Surf. Coat. Technol., Vol.124 (2000), pp.117-127.

(4) Dutta Majumdar, J. and Manna, I., Laser Surface Alloying of Copper with Chromium I. Microstructural Evolution, Mater. Sci. Eng., A, Vol.268 (1999), pp.216-226.

( 5 ) Fu, Y., Batchelor, A.W., Gu, Y., Khor, K.A. and Xing, H., Laser Alloying of Aluminum Alloy AA 6061 with $\mathrm{Ni}$ and Cr. Part I. Optimization of Processing Parameters by X-ray Imaging, Surf. Coat. Technol., Vol.99 (1998), pp.287-294.

(6) Dutta Majumdar, J. and Manna, I., Laser Surface Alloying of AISI 304-Stainless Steel with Molybdenum for Improvement in Pitting and Erosion-Corrosion Resistance, Mater. Sci. Eng., A, Vol.267 (1999), pp.5059.

( 7 ) Hu, C. and Baker, T.N., The Importance of Preheat before Laser Nitriding a Ti-6Al-4V Alloy, Mater. Sci. Eng., A, Vol.290 (1999), pp.268-275.

( 8 ) Tsai, W.T., Lai, T.H. and Lee, J.T., Laser Surface Alloying of Stainless Steel with Silicon Nitride, Mater. Sci. Eng., A, Vol.183 (1994), pp.239-349.

( 9 ) Lo, K.H., Cheng, F.T., Kwok, C.T. and Man, H.C., Improvement of Cavitation Erosion Resistance of AISI 316 Stainless Steel by Laser Surface Alloying Using Fine WC Powder, Surf. Coat. Technol., Vol.165 (2003), pp.258-267.

(10) Shaaf, P., Laser Nitriding of Metals, Progr. Mat. Sci., Vol.47 (2002), pp.1-161.

(11) Mackwood, A.P. and Grafer, R.C. Thermal Modelling of Laser Welding and Related Processes: A Literature Review, Optics \& Laser Tech., Vol.37 (2005), pp.99115.

(12) Massalski, T.B. and Okamoto, H., Binary Alloy Phase Diagrams, (1990), p.417, ASM, Ohio.

(13) Lamb, M., West, D.R.F. and Steen, W.M. Residual Stresses in Two Laser Surface Melted Stainless Steels, Marer. Sci. Tech., Vol.2 (1986), pp.974-980.

(14) Ternary Alloys, Edited by Petzow, G. and Effenberg, G., Vol.5 (1988), p.399, VCH, Weinheim.

(15) Encyclopedia of Materials Science and Engineering, Edited by Bever, M.B., Vol.7 (1986), p.4953, Pergamon, Oxford. 